\title{
UTILIDAD DE LAS MUESTRAS DE SANGRE TOTAL DESECADA EN PAPEL DE FILTRO EN LA DETECCIÓN DE ANTICUERPOS ANTITOXOPLASMA
}

\author{
Joaquim GASCON (1), Josep M. TORRES-RODRIGUEZ (2) \& Carmen GONZALEZ (2)
}

\section{RESUMEN}

Se compara la técnica de Aglutinación Directa (AD) utilizando muestras de sangre total desecada en papel de filtro, con la técnica de ELISA y la misma AD utilizando muestras de suero de los mismos pacientes, para la detección de anti cuerpos antitoxoplasma.

Los resultados muestran la validez del método de la sangre desecada en papel de filtro para la detección de anticuerpos antitoxoplasma con la técnica de $A D$, y se considera su utilidad en los estudios epidemiológicos de campo.

UNITERMOS: Toxoplasmosis; Reacción de Aglutinación directa; Sangre total en papel de filtro.

\section{INTRODUCCION}

El estudio de la prevalencia de los anticuerpos antitoxoplasma en muestras representativas de una problación constituye un requisito indispensable para reconocer la extensión de la toxoplasmosis en la comunidad.

Diversos autores han demostrado la utilidad del método de la sangre desecada en papel de filtro para la detección de anticuerpos en enfermedades como el paludismo ${ }^{2}$, la hepatitis ${ }^{10}$, o la tripanosomiasis ${ }^{8}$ y han evidenciado las ventajas de este método que no requiere personal especializado ni utillaje sofisticado y facilita además los envios de las muestras hasta los centros de procesamiento de las mismas.

En nuestro estudio hemos ensayado esta técnica, aplicada a la detección de anticuerpos antitoxoplasma mediante la reacción de Aglutinación Directa (AD). Esta técnica ha sido utilizada por otros autores ${ }^{4.5}$ demostrando que tiene una alta sensibilidad y especificidad. Se ha comparado con los resultados obtenidos con sueros de los mismos pacientes con la técnica de $\mathrm{AD}^{5}$ y la ELISA ${ }^{1}$ técnica ésta última que se ha tomado como patrón de referencia.

\section{MATERIAL Y METODOS}

Se han estudiado muestras de suero y sangre total desecada en papel de filtro de 32 personas, escogidas al azar, provenientes del dispensario del Hospital del Mar (Barcelona), a los que se habia pedido la detección de anticuerpos antitoxoplasma ante la sospecha de enfermedad o sim. plemente como "screening" en embarazadas.

(1) Hópital Nemba, Rwanda

(2) Servei Microbiologia Clínica, Hospital del Mar, Barcelona, España.

Dirección para la correspondencia: Dr. Josep M. Torres-Rodriguez. Servei Microbiologia Clínica - Hospital del Mar. Passeig Maritim, 25-27. 08003 Barcelona. España. 
GASCON, J.. TORRES RODRIGUEZ, J. M. \& GONZALEZ, C. - Utilidad de las muestras de sangre total desecada en papel de filtro en la deteccion de anticuerpos antitoxoplasma. Rev. Inst. Med. trop. Sāo Paulo. 31 i2): 100102 1989.

Las muestras se obtuvieron por punción ve nosa. De cada paciente se separaron tres gotas de sangre que se depositaron en papel de filtro. Cada gota de sangre ocupaba un área de $15 \mathrm{~mm}$. de diametro. Los papeles de filtro se dejaron se car a la temperatura ambiente y luego guarda dos a $4 \mathrm{C}$ hasta el momento de su utilización. El resto de la sangre se centrifugó para la obtención de suero que se guardó a $-20 \mathrm{C}$ hasta el momento de ser procesadas.

Para la elución de los papeles de filtro se empleó $0.5 \mathrm{ml}$ de tampón fosfato (PBS) durante 24 horas a $4 \mathrm{C}$.

Para la técnica de AD se utilizaron los kits de Toxo-screen DA (Biomérieux, Lyon ${ }^{4}$ ). De ca da muestra se emplearon dos diluciones en PBS. a $1 / 20$ y $1 / 80$, que después del proceso seguido con la técnica se encontraron a diluciones de 1/40 y 1/160 respectivamente. El título de 1/40 es el valor discriminativo entre una reacción po sitiva y una de negativa.

La lectura se hace a las cinco horas después de la dilución de la sangre o suero problema tra tados con el 2-mercaptoetanol (2-ME) y la sus pensión de antigeno, dejando reposar los po cillos a la temperatura ambiente, al resguardo de la desecación y las vibraciones.

La lectura, que es macroscópica, puede repe tirse a las 18 horas siendo ésta muy fácil: reac ción positiva cuando la aglutinación de los toxo plasmas en forma de velo tapiza como minimo la mitad del fondo del pocillo, pudiendo estar retraido en los bordes; reacción negativa cuando los toxoplasmas sedimentan en botón o anillo.

Como técnica de referencia se empleó un en zima immuno-ensayo en fase sólida, determinan do IgG contra Toxoplasma gondii (Labsystems Helsinki ${ }^{1}$ ). Conforme con los fabricantes, un va Ior de $10 \mathrm{UI}$ (equivalentes a 1.0 de densidad ópti ca) o superior se consideran positivos

\section{RESULTADOS}

Mediante el test de ELISA, 17 de los sueros dieron resultado positivo y 15 negativo.

Con la técnica de $A D$, los resultados fueron 16 positivos y 16 negativos tanto en las muestras de sangre total desecada en papel de filtro como en las muestras de suero. Excepto en una pacien te que dió positivo en el test de ELISA (valor de 21 UI) y negativo en los tests de AD, la concor dancia de resultados fue total en el resto de las muestras.

Se observaron dos fenómenos de prozona en dos muestras en las que se utilizó suero con la técnica de $\mathrm{AD}$ (negativo a 1/40 y positivo a 1/160). En ambos casos los resultados fueron positivos con las muestras de sangre total desecada, sin que se observara el fenómeno de prozona.

Tomando como técnica de referencia el test de ELISA, la sensibilidad del método fue del $94 \%$ y la especificidad del $100 \%$. Al observar Ios resul tados con la técnica de ELISA entre los sueros positivos, se encontraron diferentes grados de reactividad (tabla 1 . Al comparar las tres técni cas entre si, los resultados obtenidos no mues tran diferencias estadisticamente significativas $\left(\mathrm{X}^{2}=0.08\right)$.

TABLA

Reartividad de las muestras en el test de ELISA

\begin{tabular}{cccccccc}
\hline & & \multicolumn{9}{c}{ UI } & & & \\
& 10 & 1015 & 1620 & 2125 & 2630 & 3135 \\
\hline $\mathrm{n}$ sueros & 15 & 2 & 5 & 2 & 6 & 2 \\
\hline
\end{tabular}

UI: Unidades Internacionales.

\section{DISCUSION}

La técnica de AD, fue descrita por FULTON \& TURK $^{6}$ y ampliada por los trabajos de COU. ZINEAU \& BAUFINE-DUCROQ ${ }^{4}$ y DES MONTS $^{5}$, que incluyeron en ella el 2-ME y un antigeno de mayor calidad que mejoraban tanto la sensibilidad como la especificidad.

En nuestro estudio no hubo diferencias entre los resultados de las muestras de sangre y plas ma procesados por AD, y tomando como técnica de referencia el test de ELISA, la especificidad y la sensibilidad fueron similares a las de ésta última.

La técnica de AD ha sido ya evaluada como técnica de "screening" en estudios epidemiolo gicos ${ }^{4.5}$ aunque siempre se habian utilizado sue 
GASCON, J : TORRES RODRIGUEZ, J. M. \& GONZALEZ, C. - Utilidad de las muestras de sangle total desecada en papel de filtro en la deteccion de anticuerpos antitoxoplasma. Rev. Inst. Med. trop. Säo Paulo, 31 ,2: 100 102 1989

ros. Otros autores han valorado la utilidad de la sangre total desecada en papel de filtro con técricas distintas de la $A D^{3 .}$. Los resultados obtenidos en este estudio muestran que la tecni. ca de desecación de sangre total en papel de filtro es útil para la obtención de muestras váli das para su procesamiento con la técnica de AD.

La posibilidad de obtener la sangre a través de una simple punción digital ${ }^{2}$ facilita aún inas la obtención de muestras en estudios epidemiológicos de masas.

Otra ventaja para detectar anticuerpos IgG es que en la sangre desecada, se ha descrito la desnaturalización de las $\operatorname{IgM}^{7}$ lo que favoreceria la acción del 2-ME de la $\mathrm{AD}$, en el aumento de especificidad de la prueba.

Los fenómenos de prozona han sido descri tos con esta técnica ${ }^{5}$. En estudios epidemiolo gicos este fenómeno pierde su importancia, aun que si se quiere una buena precisión, pueden procesarse dos diluciones de una misma mues. tra.

En conclusión, la técnica de la gota de san gre desecada en papel de filtro y procesada me. diante la técnica de $A D$, que es de una gran sen cillez y fácil lectura, puede ser de gran utilidad para los estudios epidemiológicos sobre la preva lencia de la toxoplasmosis, asi como en estudios en pequeños animales.

\section{SUMMARY}

Usefulness of dry blood samples on filter paper in the detection of antitoxoplasma antibodies.

Direct Agglutination (DA) techniques, both, using dry blood samples in filter paper and serum samples, were compared with the ELISA test in order to detect antibodies against Toxoplasma gondii.
The results show the validity of the dry blood samples in filter paper for detecting antitoxo plasma antibodies with a DA test. Our results would confirm their usefulness in field epidemio logical surveys.

\section{REFERENCIAS}

1. BALFOUR. A. H. \& HARFORD. J. P. Detertion of spe cific IgG and IgM antibodies to Toxoplasma gondii with a commercially avallable enzyme immunoassay kit system J. clin. Path., 38: 679 689, 1985.

2. BRUCE CHWATT, L. J. Diugnostic mothodsinmalarla In: BRUCE CHWATT, L. J -.. Essential malariology. 2nd ed. London, Heinemann, 1985. p. 101126

3. COUTinHo, S. G. - Aplicacáo da tecnica do coleta do sangue total em disco de papel para o diagnósticn da toxo plasmose pelas reacoes de imunofluoresencia indireta e Sabin Feldman Rev. Soc. hras. Med. trop., 4(supl): 2122, 1970 .

4. COUZINEAU, P. \& BAUfine DUCROQ, H. - A Aggluti nation directe des toxoplasmes. Preparation de l'antigene et examen de 400 serums. Ann. Biol. clin.. 28: 411415 1970.

5. DESMONTS, G.-- Depistage de la toxoplasmose par ag glutination des parasites. Interet d un antigene tres sensi ble pour la recherche des immunogtobulines $G$ specif ques. Ann. Biol. clin., 41: 139143,1983

6. FULTON. J. D. \& TURK. J. L. - Direct agglutination for Toxoplasma gondii. Lancet, 2: 10681069,1959

7. SEROLOGICAL testing in malaria. Bull. Wid. MIth. Org., 50: 527535,1974

8. SOUZA. S. L. \& CAMARGO. M. E. - The use of filter paper blood smears in a practical fluorescent test for Ame rican Trypanosomiasis scro diagnosis. Rev. Inst. Med. trop. S. Paulo, 8: $255258,1966$.

9. WALLACE. G. D. - Sabin Feldman dye test for toxoplas mosis. The use of sodium citrate in accessory factor and a method for collecting and storing blood on paper disc Amer. J. trop. Med. Hyg., 18:395 398, 1969

10. ZHUANG, H.: COULEPIS. A. G.: LOCARNINI, S. A \& GUST. I. D. - Detection of markers of hepatitis $B$ infee tion in serum dried on to filter paper: an application to field studies. Bull. Wld. Hlth. Org., 60:783 787, 1982.

Recebido para publicaçá em 30.81988 